Check for updates

Cite this: Chem. Sci., 2018, 9, 8883

๑ All publication charges for this article have been paid for by the Royal Society of Chemistry

Received 24th July 2018

Accepted 23rd September 2018

DOI: $10.1039 / \mathrm{c} 8 \mathrm{sc} 03267 \mathrm{j}$

rsc.li/chemical-science

\section{Phenolation of cyclodextrin polymers controls their lead and organic micropollutant adsorption $\uparrow$}

\author{
Max J. Klemes, (D) a Yuhan Ling, (D) ${ }^{b}$ Marta Chiapasco, ${ }^{a}$ Alaaeddin Alsbaiee, ${ }^{c}$ \\ Damian E. Helbling (D) *b and William R. Dichtel (D)*a
}

Porous $\beta$-cyclodextrin polymers linked with tetrafluoroterephthalonitrile (TFN-CDPs) have shown promise for adsorbing organic micropollutants (MPs) more quickly and effectively than conventional adsorbents. Prior to their discovery, the nucleophilic aromatic substitution $\left(S_{N} A r\right)$ reaction used to prepare TFN-CDP was nearly unknown for the aliphatic alcohol nucleophiles, and the low isolated yields of TFN-CDP motivated model studies of the reaction between TFN and $n$-butanol. These experiments reveal a previously undescribed substitution reaction of TFN in which a fluorine is substituted by a hydroxyl group. This process is responsible for the low yields of the polymerization and incorporates phenolate groups into the polymer network. Phenolation and polymerization (etherification) are competing processes, and the level of phenolate incorporation was controlled by varying the rate of base addition and initial monomer concentrations. TFN-CDPs with varying phenolate content were prepared and evaluated as adsorbents for both $\mathrm{Pb}^{2+}$ ions and 83 MPs. More heavily phenolated polymers showed increased capacity to bind $\mathrm{Pb}^{2+}$ ions. Phenolation was also correlated with increased binding affinity for almost all of the 83 MPs tested, including neutral, cationic, and anionic substances. These results leverage a newly discovered side reaction during $\mathrm{S}_{N} A r$ reactions of electron-poor aryl fluorides to improve both the yield and the uptake affinity for both lead and organic MPs of TFN-CDPs.

\section{Introduction}

The contamination of groundwater and surface water by heavy metals and organic micropollutants (MPs) is a world-wide problem..$^{1-4}$ There is no safe level for lead in drinking water. ${ }^{5}$ Low concentrations of MPs ( $\mu \mathrm{g}$ to $\mathrm{ng} \mathrm{L}^{-1}$ ) can have deleterious effects in aquatic ecosystems, ${ }^{6-8}$ and long-term exposure to complex MP mixtures in drinking water may contribute to health and behavioral problems in humans. ${ }^{9}$ Currently, the economically scalable methods of water treatment for organic MPs are advanced oxidation ${ }^{10}$ and activated carbon (AC) adsorption. ${ }^{11}$ Advanced oxidation effectively reduces the concentration of organic MPs in water but can leave behind partially oxidized byproducts that retain toxic activity. ${ }^{12,13} \mathrm{AC}$ adsorption effectively removes organic MPs but requires energyintensive regeneration ${ }^{14}$ and can be fouled by natural organic matter. ${ }^{15}$ These problems might be addressed by using

${ }^{a}$ Department of Chemistry, Northwestern University, Evanston, IL 60208, USA. E-mail: wdichtel@northwestern.edu

${ }^{b}$ School of Civil and Environmental Engineering, Cornell University, Ithaca, NY 14853, USA

'Department of Chemistry and Chemical Biology, Cornell University, Ithaca, NY 14853, USA

$\dagger$ Electronic supplementary information (ESI) available: Experimental procedures, $\mathrm{Pb}^{2+}$ binding isotherms and affinity plots, ${ }^{1} \mathrm{H},{ }^{13} \mathrm{C}$, and ${ }^{19} \mathrm{~F}$ NMR spectra, FT-IR Spectra. See DOI: $10.1039 / \mathrm{c} 8 \mathrm{sc} 03267 \mathrm{j}$ cyclodextrin (CD)-based adsorbents, which form well-defined host-guest complexes, ${ }^{16-18}$ are readily regenerated, ${ }^{19}$ and can exhibit rapid micropollutant removal. ${ }^{20}$ Cyclodextrin polymers and other porous, bio-derived materials have been used in water purification to remove pollutants including: phenolic molecules, ${ }^{21,22}$ dyes, ${ }^{23-25}$ naphthenic acids ${ }^{26}$ perfluoroalkylated acids, ${ }^{27}$ and heavy metals. ${ }^{28,29}$ We previously reported porous polymer networks prepared via a nucleophilic aromatic substitution $\left(\mathrm{S}_{\mathrm{N}} \mathrm{Ar}\right)$ polyaddition between $\beta-\mathrm{CD}$ and tetrafluoroterephthalonitrile (TFN-CDP-1). ${ }^{30}$ TFN-CDP-1 had a Brunauer-Emmett-Teller surface area of $260 \mathrm{~m}^{2} \mathrm{~g}^{-1}$ and exhibited more rapid uptake for many MPs compared to leading ACs and low-surface-area CDPs. The adsorbent was regenerated easily, was not fouled by humic acid in simulated surface water, ${ }^{20}$ and was further developed as a promising resin for solid-phase microextraction. ${ }^{19}$ However, the yield of the material obtained from the initial polymerization conditions was low $(18 \%)$, and the TFN : $\beta$-CD ratio of the isolated polymer ( $c a$. $6: 1)$ did not match the monomer feed ratio $(3: 1) .^{30}$ Furthermore, while polycondensations of TFN with catechols provide high molecular weight polymers that indicate efficient and selective reactions, ${ }^{31}$ there was only a single prior example of an $\mathrm{S}_{\mathrm{N}} \mathrm{Ar}$ reaction between TFN and an aliphatic alcohol. ${ }^{32}$ Here we report a phenolation side-reaction of TFN that competes with its $\mathrm{S}_{\mathrm{N}} \mathrm{Ar}$ reactions with aliphatic alcohols. Although this process contributed to the low yields of TFN-CDP in our previous report, 


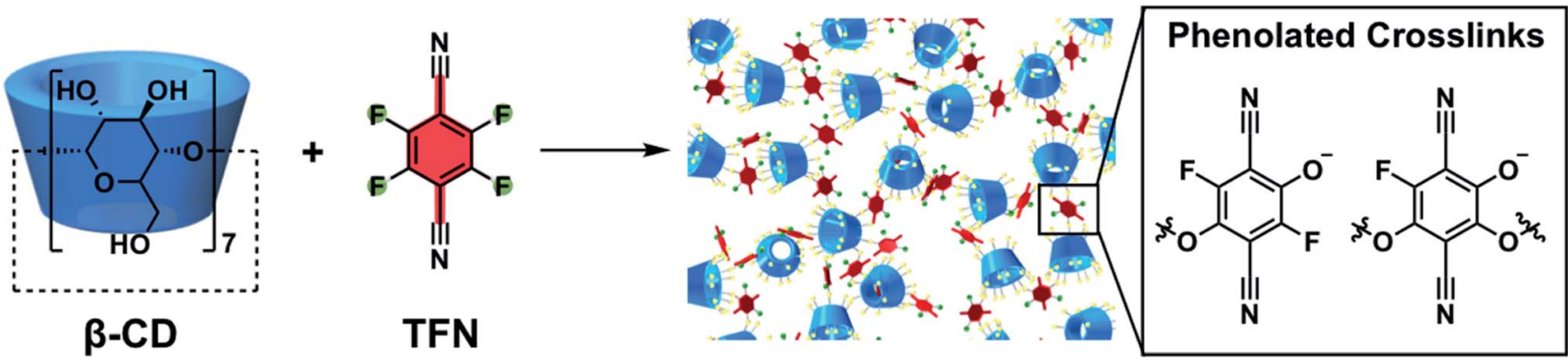

\section{Improved Yields / $\mathrm{Pb}^{2+}$ Binding / Improved Micropollutant Affinity}

Fig. 1 Synthesis of $\beta$-cyclodextrin ( $\beta-C D)$ polymers linked with tetrafluoroterephthalonitrile. This study identifies phenolated TFN-derived species incorporated into the polymer and characterizes their effect on $\mathrm{Pb}^{2+}$ and organic micropollutant binding

we now balance the rates of phenolation and productive etherification reactions to improve polymerization yields and tune adsorbent performance (Fig. 1). Phenolated TFN-CDPs bind both organic micropollutants and $\mathrm{Pb}^{2+}$ ions more effectively than similar polymers with fewer phenolates. These findings demonstrate the promise and tunability of $\mathrm{CD}$ polymer networks to purify contaminated water. Identifying and controlling the loading of these phenolate functional groups in TFN-CDPs is therefore important for maximizing their performance and manufacturability. Furthermore, TFN is a common monomer in other classes of porous polymers ${ }^{31,33-36}$ and understanding its reactivity with aliphatic hydroxyl groups will significantly broaden the scope of potential comonomers.

\section{Results and discussion}

\section{Model studies}

TFN-CDP-1 was prepared in THF in 18\% isolated yield under similar conditions as our previous report; ${ }^{30}$ it is synthesized via a $\mathrm{S}_{\mathrm{N}} \mathrm{Ar}$ polycondensation in which the alcohol groups of $\beta$-CD are deprotonated by $\mathrm{K}_{2} \mathrm{CO}_{3}$. Yield is defined throughout this work as (mass of isolated TFN-CDP)/(mass of the monomers), because the theoretical yield depends on both the efficiency of monomer incorporation and the number of $\mathrm{S}_{\mathrm{N}} \mathrm{Ar}$ reactions that occur. Furthermore, the ratio of TFN : $\beta$-CD $(6: 1)$ found in the isolated polymer deviated from the monomer feed ratio $(3: 1$ TFN : $\beta$-CD). The low yield and difference between the monomer feed and incorporation ratios were suggestive of side reactions, which motivated us to study the reactivity of TFN. Polymerizations in DMSO (TFN-CDP-2) provided higher yields (64\%) compared to TFN-CDP-1, even at shorter reaction times $(18 \mathrm{~h} v s .48 \mathrm{~h}$ ). A monomer feed ratio of $6: 1 \mathrm{TFN}: \beta-\mathrm{CD}$ provided an incorporation ratio of $5.2: 1$, corresponding to a loss of 0.8 equiv. ( $13 \mathrm{~mol} \%)$ of the TFN. After isolating the insoluble polymer, analysis of the soluble fraction by ${ }^{19} \mathrm{~F}$ and ${ }^{13} \mathrm{C}$ NMR spectroscopy and high-resolution mass spectrometry indicated the formation of phenolate $\mathbf{1 b}$ as a major side product. We hypothesized that $\mathbf{1 b}$ is formed via the $\mathrm{S}_{\mathrm{N}} \mathrm{Ar}$ of TFN and $\mathrm{K}_{2} \mathrm{CO}_{3}$, followed by decarboxylation. Indeed, $\mathbf{1 b}$ is formed quantitatively within 10 min when TFN $(0.3 \mathrm{mM})$ and $\mathrm{K}_{2} \mathrm{CO}_{3}(3.3$ equiv.) are combined in anhydrous DMSO at $80{ }^{\circ} \mathrm{C}$ (Scheme 1), as measured by ${ }^{19} \mathrm{~F}$ NMR spectroscopy. Evidence for this side reaction under the polymerization conditions, combined with the rapid formation of $\mathbf{1 b}$ in the absence of other nucleophiles, suggested that further study of the phenolation of TFN might improve the yield of the polymerization.

Model $\mathrm{S}_{\mathrm{N}} \mathrm{Ar}$ reactions between TFN and $n$-butanol show that phenolation and etherification reactions are in competition. Etherification and phenolation both proceed slowly in THF over $48 \mathrm{~h}$. The dominant product observed by ${ }^{19} \mathrm{~F}$ NMR spectroscopy was the monosubstituted ether 1a (78\%). Minor products included a mixture of dibutyl ethers $\mathbf{2 a}(6 \%)$ and phenolate $\mathbf{1 b}$ (8\%). More highly substituted ethers and phenolate products were observed when the reaction was run in DMSO for $9 \mathrm{~h}$. These higher substituted products may explain why the polymerization is both faster and higher yielding in DMSO. The major products (Scheme 2) were the trisubstituted ether 3a (43\%), 1b (34\%), a mixture of regioisomers containing one phenolate and one ether $(\mathbf{2 b}, \mathbf{2} 1 \%)$, and a mixture of disubstituted ethers (2a, 2\%). Phenolation is enhanced in this solvent, and $\mathbf{1 b}$ is much less active for further substitutions as compared to the etherification products. When a pure sample of phenolate 1b was subjected to these reaction conditions, only $4 \%$ conversion to the 1,2-substituted regioisomer of $2 \mathbf{b}$ was

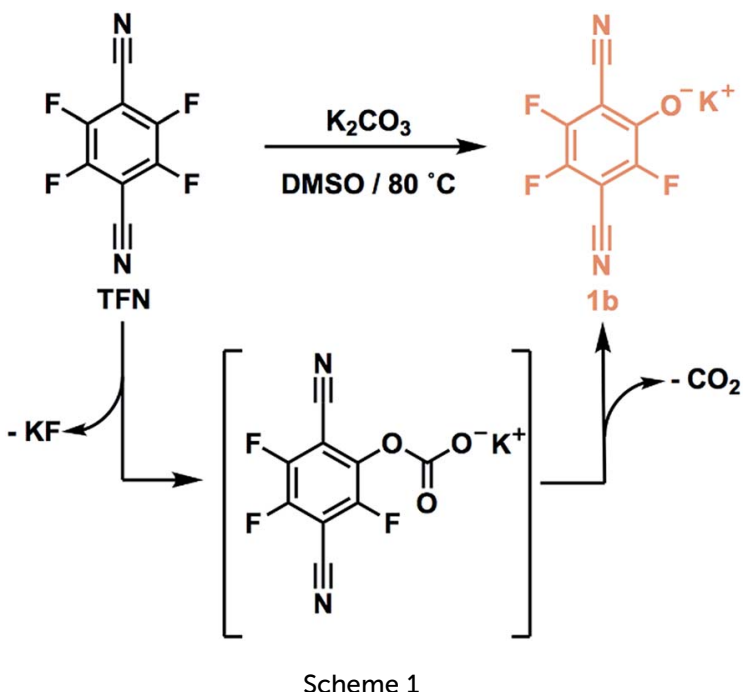




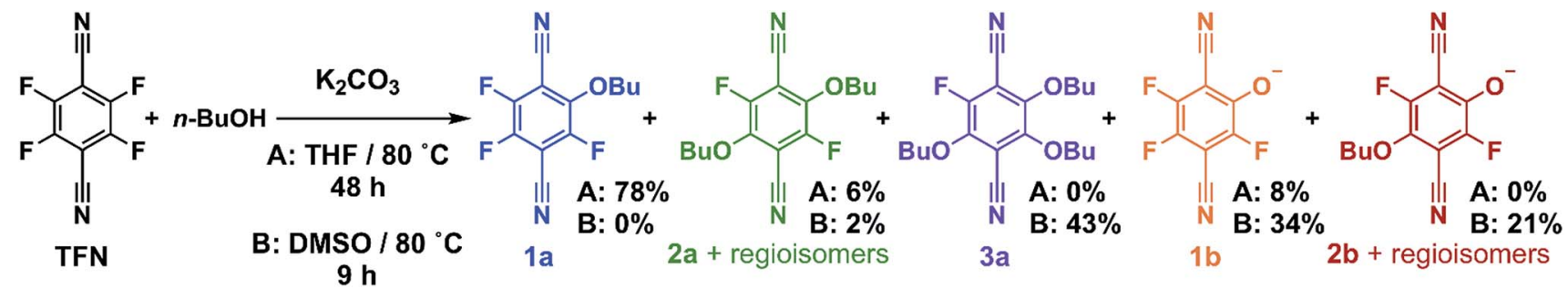

Scheme 2

observed after $24 \mathrm{~h}$, indicating that $\mathbf{2 b}$ forms via $1 \mathrm{a}$. A model reaction in DMSO monitored by ${ }^{19} \mathrm{~F}$ NMR spectroscopy as a function of reaction time also demonstrates that phenolated products essentially do not undergo further reactions in the presence of competing electrophiles (Fig. 2a). Most of the TFN is consumed within $10 \mathrm{~min}$, with $59 \%$ conversion to $1 \mathrm{a}$ and $30 \%$ conversion to $\mathbf{1 b}$. 1a continues to react to form more highly substituted products, whereas the concentration of $\mathbf{1 b}$ remains approximately constant over $9 \mathrm{~h}$. Most of $1 \mathrm{a}$ reacts within $2 \mathrm{~h}$ to provide dibutyl ethers $\mathbf{2 a}$ and phenolates $\mathbf{2} \mathbf{b}$, which also persist for the remainder of the reaction. $\mathbf{2 a}$ reacts further to provide $\mathbf{3 a}$ over the next several hours, and no evidence for the formation of dibutyl-ether/monophenolates (3b) was observed (Fig. 2b).
These results provide significant insight into the formation of TFN-CD polymers. First, the competition between the first etherification and phenolation process in the first few minutes of the reaction are likely to influence yield and total incorporation of TFN derivatives in the resulting polymer since $\mathbf{1 b}$ is mostly unreactive. Furthermore, the formation of $\mathbf{2 b}$ demonstrates a process by which phenolate groups might be incorporated into the polymer.

The apparent competition between etherification and phenolation suggested that slow addition of the $\mathrm{K}_{2} \mathrm{CO}_{3}$ might suppress phenolation. A model reaction in DMSO in which $\mathrm{K}_{2} \mathrm{CO}_{3}$ was added gradually (3.3 equiv., 0.1 equiv. per $\mathrm{h}$ ) provided sequential etherification from $1 \mathbf{a}$ to $2 \mathbf{a}$ to $\mathbf{3 a}$ (Fig. $2 \mathrm{c}$ ) as
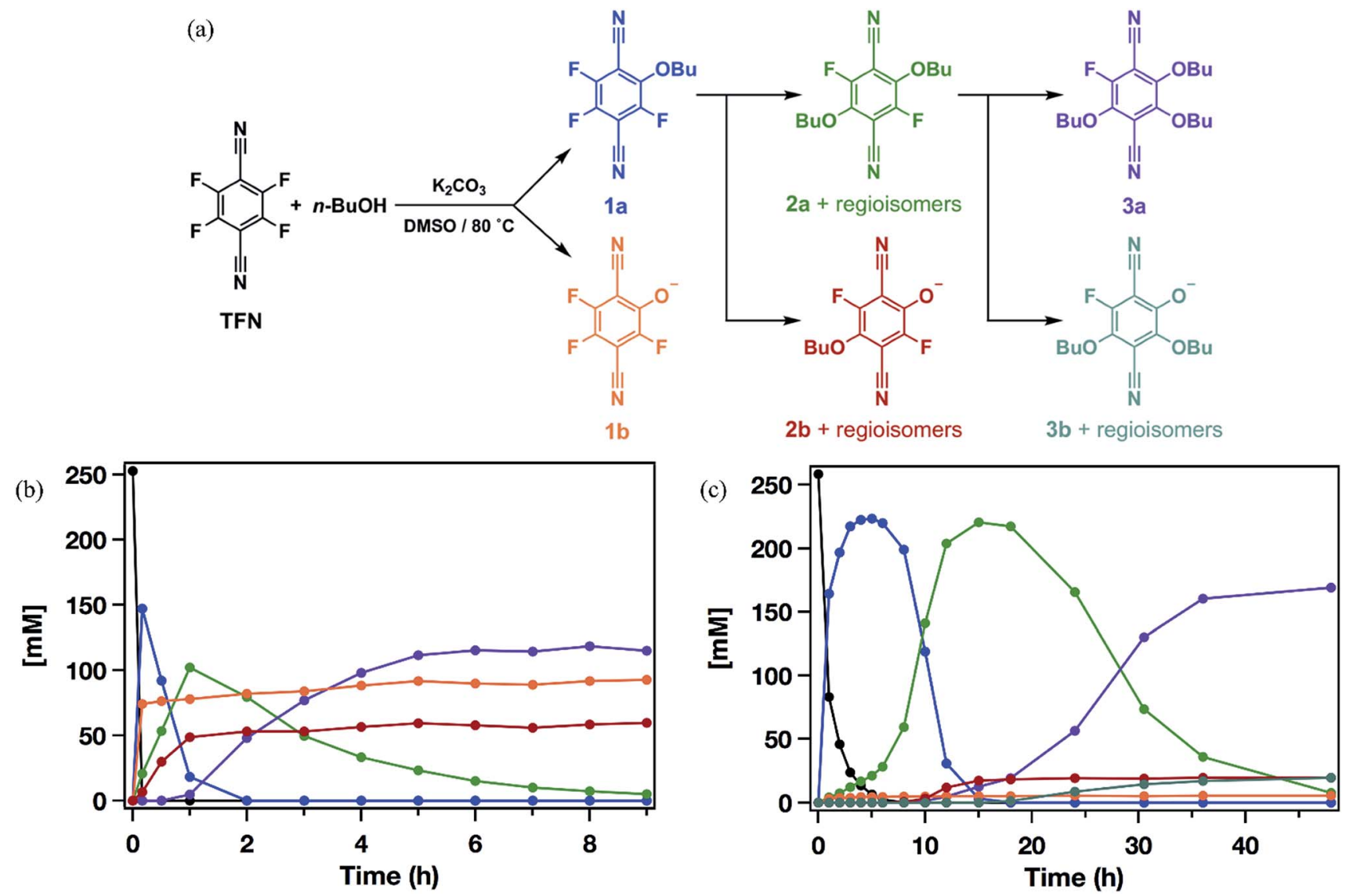

Fig. 2 (a) Reaction pathways for the formation of $n$-butoxy and phenolate-substituted TFN derivatives. (b) Concentrations of each species as a function of reaction time observed when 3.3 equiv. $\mathrm{K}_{2} \mathrm{CO}_{3}$ is added at $t=0$. (c) Concentrations of each species as a function of reaction time observed when 3.3 equiv. $\mathrm{K}_{2} \mathrm{CO}_{3}$ was added at 0.1 equiv. per $\mathrm{h}$. 
the dominant reaction pathway. After $6 \mathrm{~h}, 87 \%$ of the TFN was converted to $\mathbf{1 a}$, and only $2 \%$ proceeded to $\mathbf{1 b}$. This selectivity corresponds to a $94 \%$ reduction in phenolation relative to when $\mathrm{K}_{2} \mathrm{CO}_{3}$ is added at once. As before, $1 \mathrm{a}$ reacts to form more substituted products, and the concentration of $\mathbf{1 b}$ does not decrease at longer reaction times. After $15 \mathrm{~h}$, the conversion to 2b was only $7 \%$, and the combined regioisomers of $2 \mathbf{a}$, represented $85 \%$ of the TFN-derived species. The concentration of the $\mathbf{2 b}$ regioisomers also remain approximately constant for the remainder of the reaction, and 2 a proceeds to the trisubstituted product, 3a, and the dibutoxy phenolate products, 3b. After $48 \mathrm{~h}$, 3a made up 76\% of the TFN-derived species, as compared to $43 \%$ when the base is present throughout the reaction. We attribute the formation of $\mathbf{3} \mathbf{b}$ to the near-complete consumption of $n$-butanol at the later stages of the reaction. These experiments demonstrate that phenolation occurs readily in the presence of excess $\mathrm{K}_{2} \mathrm{CO}_{3}$ and that etherification is favored when the concentration of base is kept low. Therefore, the rate of $\mathrm{K}_{2} \mathrm{CO}_{3}$ addition might influence both the yield and degree of phenolate incorporation into TFN-CDP polymers.

\section{Polymer synthesis and characterization}

The above findings suggest that the $\mathrm{K}_{2} \mathrm{CO}_{3}$ addition rate will also affect the yield and properties of TFN-CDP (Scheme 3). For example, the formation of $\mathbf{1 b}$ during the polymerization would decrease the yield as further substitution reactions on this species are slow. Later phenolation processes, analogous to the formation of $\mathbf{2} \mathbf{b}$ or $\mathbf{3} \mathbf{b}$, do not decrease yield but incorporate phenolated TFN groups into the polymer network. We performed two polymerizations, either at $[\mathrm{TFN}]=0.33 \mathrm{M}$ and 0.17 equiv. $\beta-\mathrm{CD}$, to which 3.3 equiv. $\mathrm{K}_{2} \mathrm{CO}_{3}$ were added all at once (TFN-CDP-2) or at 0.1 equiv. per h (TFN-CDP-3). The suppression of $\mathbf{1 b}$ is reflected in the combustion analysis of the two polymers. The $\mathrm{C}: \mathrm{N}$ ratio was used to determine the number of TFN per $\beta$-CD. TFN-CDP-2 exhibits a TFN : $\beta$-CD ratio of 5.2, corresponding to a loss of 0.8 equiv. (13 mol\%) TFN to 1b. TFNCDP-3 had a TFN : $\beta$-CD ratio of 5.9 , which indicates that only 0.1 equiv. ( $2 \mathrm{~mol} \%$ ) of the TFN was lost to the first phenolation process. TFN-CDP-2 and TFN-CDP-3 also had a different concentration of phenolate incorporated into the polymers (Table 1). The phenolate concentration in the polymers was determined by deprotonating the phenolates using $\mathrm{Li}_{2} \mathrm{CO}_{3}$ and determining the amount of bound Li ions using inductively coupled plasma optical emission spectroscopy (ICP-OES, see ESI $\uparrow$ for detailed analysis procedures). To further validate this method, we performed a similar analysis of $\mathrm{K}^{+}$content in the polymers by using $\mathrm{K}_{2} \mathrm{CO}_{3}$ in place of $\mathrm{Li}_{2} \mathrm{CO}_{3}$ and found similar phenolate loadings (Table S1 $\dagger$ ). TFN-CDP-2 had a higher phenolate concentration $\left(0.44 \mathrm{mmol} \mathrm{g}^{-1}\right)$ compared to TFNCDP-3 $\left(0.22 \mathrm{mmol} \mathrm{g}^{-1}\right)$. These results are consistent with the model studies and demonstrate a means to control the phenolate concentration within the polymer networks.

Further manipulation of the phenolate loading was achieved by using higher monomer concentration in the polymerization. TFN is no longer fully soluble under the reaction conditions at a concentration of $1.2 \mathrm{M}$. A TFN-CDP formulation was prepared (TFN-CDP-4) using a concentration of $1.2 \mathrm{M}$ and by adding the $\mathrm{K}_{2} \mathrm{CO}_{3}$ all at once. TFN-CDP-4 has fewer phenolates $(0.14 \mathrm{mmol}$ $\left.\mathrm{g}^{-1}\right)$ compared to TFN-CDP-2 $\left(0.44 \mathrm{mmol} \mathrm{g}^{-1}\right)$, which is formed under similar conditions but lower initial monomer concentration. In the synthesis of TFN-CDP-4, the volume of DMSO was decreased four-fold, which renders a portion of the TFN undissolved and effectively increases the ratio of $\beta-C D$ to dissolved TFN compared to reactions run at lower concentration. This higher effective ratio of $\beta$-CD alcohols to TFN-fluorides favors etherification over phenolation. Finally, combining both effects that provide lower phenolate concentration, TFNCDP-5 was synthesized using gradual $\mathrm{K}_{2} \mathrm{CO}_{3}$ addition (0.1 equiv. per h) and high concentration $(1.2 \mathrm{M})$, which provided the lowest concentration of bound phenolate $\left(0.08 \mathrm{mmol} \mathrm{g}^{-1}\right)$ (Scheme 3). The results of these polymerizations demonstrate that CD-TFN polymers with varying phenolate concentrations can be accessed by exploiting the competition between etherification and phenolation.

\section{$\mathbf{P b}^{2+}$ capacity}

He and coworkers recently reported that a polymer synthesized under similar conditions as TFN-CDP-1 binds $\mathrm{Pb}^{2+}$ ions with

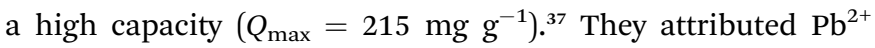
binding to interactions with the hydroxyl groups of $\beta-\mathrm{CD}$, but the possible presence of phenolates in the polymers was not yet recognized. We evaluated TFN-CDP polymer samples of varying phenolate content to determine their role in sequestering $\mathrm{Pb}^{2+}$ ions. The $Q_{\max }$ of each polymer was determined by batch experiments in which the polymers were exposed to $\mathrm{Pb}\left(\mathrm{NO}_{3}\right)_{2}$ solutions $(1-50 \mathrm{ppm}, \mathrm{pH}=5)$ for $24 \mathrm{~h}$. After removing the polymers by filtration, the $\mathrm{Pb}^{2+}$ concentrations were determined via ICP-OES. The $\mathrm{Pb}^{2+}$ removal was determined by the concentration difference between the polymer treated solution and control solutions not exposed to polymers. $Q_{\max }$ was

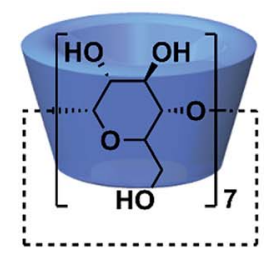

$\beta-C D$

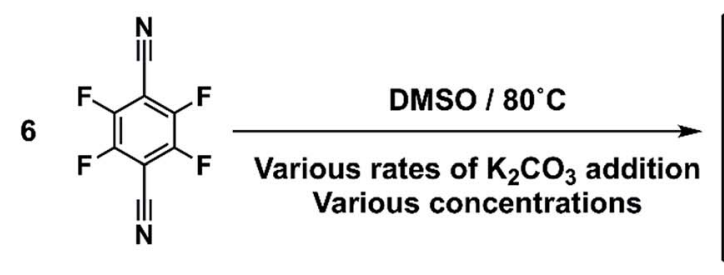

TFN

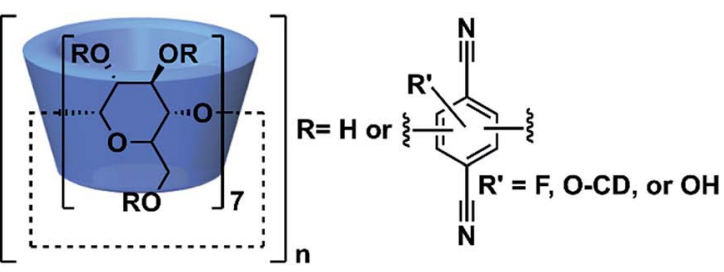

TFN-CDP-2-TFN-CDP-5 
Table 1 Polymerization conditions, bound phenolate concentrations, and TFN : CD ratio in polymer samples ${ }^{a}$

\begin{tabular}{|c|c|c|c|c|c|c|}
\hline Polymer & {$\left[\right.$ Phenolate] $\left(\mathrm{mmol} \mathrm{g}^{-1}\right)$} & $\mathrm{K}_{2} \mathrm{CO}_{3}$ addition rate & {$[\mathrm{TFN}]_{0}(\mathrm{M})$} & TFN : CD ratio & $S_{\mathrm{BET}}\left(\mathrm{m}^{2} \mathrm{~g}^{-1}\right)$ & Yield (\%) \\
\hline TFN-CDP-2 & $0.44(+/-0.01)$ & At once & 0.3 & 5.2 & $346(+/-113)$ & 64 \\
\hline TFN-CDP-3 & $0.22(+/-0.02)$ & 0.1 equiv. per $h$ & 0.3 & 5.9 & Non-porous & 67 \\
\hline TFN-CDP-5 & $0.08(+/-<0.01)$ & 0.1 equiv. per $\mathrm{h}$ & 1.2 & 5.9 & Non-porous & 54 \\
\hline
\end{tabular}

${ }^{a}$ TFN-CDP refers to tetrafluoroterephthalonitrile-linked $\beta$-cyclodextrin polymer.

determined by building an isotherm of the average solid phase concentration of $\mathrm{Pb}^{2+}$ verses the aqueous concentration of $\mathrm{Pb}^{2+}$ and fitting this to the Langmuir model. The $Q_{\max }$ for TFN-CDP1-TFN-CDP-5 was 16.4-2.4 $\mathrm{mg} \mathrm{g}^{-1}$ (Fig. 3). Polymers prepared in DMSO (TFN-CDP-2-TFN-CDP-5) with varying phenolate content showed a strong positive correlation between $\mathrm{Pb}^{2+}$ capacity and phenolation, TFN-CDP-1 was also found to have a high phenolate content and exhibited a reasonable capacity for $\mathrm{Pb}^{2+}$, but not as high as TFN-CDP-2. Unlike TFN-CDP-2-TFN-CDP-5, TFNCDP-1 was synthesized under different conditions (THF) under which $\beta$-CD is insoluble. Therefore, it may have other structural differences, such as variations in local TFN functionalization density or regioselectivity in its reactions with $\beta$-CD that also influence its $\mathrm{Pb}^{2+}$ binding. We have not explored these differences further because TFN-CDP-1 is difficult to scale up and shows lower $\mathrm{Pb}^{2+}$ binding capacity than TFN-CDP-2. Although the $S_{\mathrm{BET}}$ of the materials are different, it is likely that the polymer is fully accessible to pollutants at equilibrium. This point is consistent with bisphenol-A (BPA) isotherms generated for each of the polymers (Fig. S4 $\dagger$ ), from which Langmuir fits provided high $Q_{\max }(>1$ BPA : $\beta$-CD) for both porous and non-porous polymers. Therefore, the differences in $Q_{\max }$ for $\mathrm{Pb}^{2+}$ binding likely arise from the variation in phenolate loading of each polymer. Finally, it is important to note that all of our polymers show approximately 20 fold inferior capacity to the very high value $\left(215 \mathrm{mg} \mathrm{g}^{-1}\right)$ reported by He and coworkers ${ }^{37}$ for a polymer prepared similarly to TFN-CDP-1. The discrepancy between our measured values and this report cannot be readily explained.

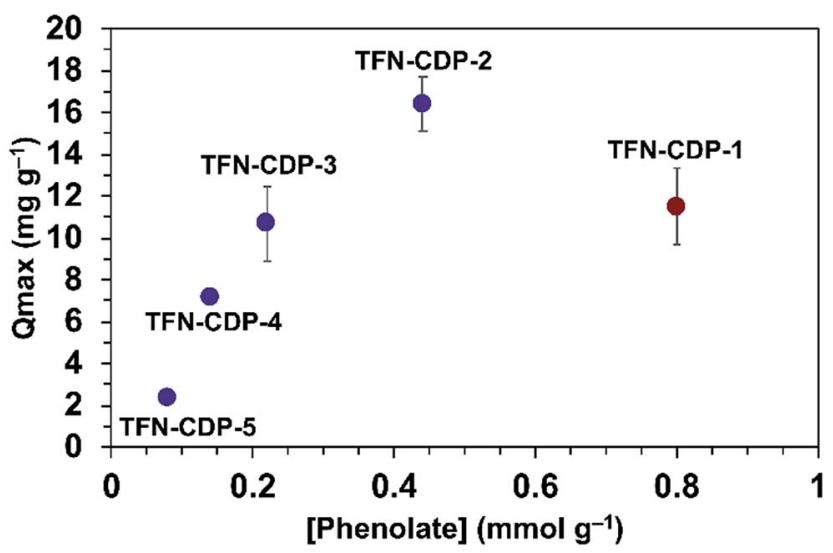

Fig. $3 Q_{\max }$ for $\mathrm{Pb}^{2+}$ as a function of bound phenolate functionalities in polymer samples TFN-CDP-1-TFN-CDP-5.
The rate of $\mathrm{Pb}^{2+}$ removal is dependent on the porosity in these polymers. To probe the importance of porosity to $\mathrm{Pb}^{2+}$ removal, the rate of $\mathrm{Pb}^{2+}$ removal $\left(\mathrm{Pb}^{2+} k_{\text {obs }}\right)$ was determined for all polymers (Fig. S6 $\dagger$ ). TFN-CDP-2 has a higher surface area than non-porous TFN-CDP-3-TFN-CDP-5 and has superior $\mathrm{Pb}^{2+}$ $k_{\text {obs }}$ compared to the other polymers. Among the non-porous polymers, the phenolate content did not have a pronounced effect on $\mathrm{Pb}^{2+} k_{\text {obs }}$ but did have an effect on the capacity at equilibrium $\left(q_{\mathrm{e}}\right)$. These results further suggest that phenolate concentration is correlated with affinity to $\mathrm{Pb}^{2+}$ ions at low concentrations.

\section{Micropollutant affinity}

MP affinity testing on all polymer samples indicate that phenolation is desirable in that these charged groups in the polymer predictably affect polymer affinity to positively charged MPs. MP affinity was determined by measuring the adsorption of a mixture of 83 MPs at low concentrations $\left(1 \mu \mathrm{g} \mathrm{L}^{-1} ; 1 \mathrm{ppb}\right)$ by means of HPLC-MS/MS (Table S2 $\dagger$ ). The adsorption was used to determine the affinity of each MP $\left(K_{\mathrm{D}}\right)$ for each polymer. To compare the MP affinity of highly phenolated TFN-CDP-2 with weakly phenolated TFN-CDP-5 the $\log K_{\mathrm{D}}$ for each MP for the two polymer samples was plotted on the binary chart in Fig. 4.

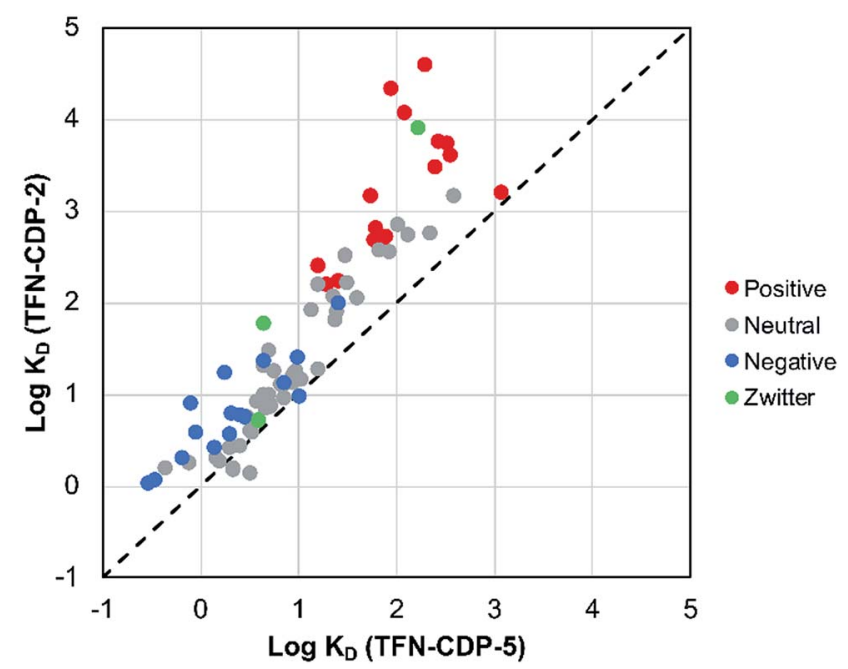

Fig. 4 Affinity experiment comparing higher-phenolate-content TFN-CDP-2 and lower-phenolate-content TFN-CDP-5. This experiment shows that TFN-CDP-2 has higher affinities for 81 of 83 micropollutants tested. 
Of the 83 micropollutants, 81 bind more strongly to the more heavily phenolated polymer. Not surprisingly, cationic substances bind with the highest $K_{\mathrm{D}}$ and show the largest differential affinity for the more heavily phenolated polymer. However, although anionic substances bind with lower affinity, they still bind to the more heavily phenolated polymer TFNCDP-2 more strongly than TFN-CDP-5. Similar affinity trends for both cationic and anionic substances were observed in pairwise comparisons of the polymers with intermediate phenolate content (Fig. S3†). These findings indicate that TFN phenolation is correlated with improved affinity for cationic MPs yet has a smaller and often non-deleterious impact on binding of anionic and uncharged substances.

The phenolate content of the non-porous samples (TFNCDP-3 through TFN-CDP-5) also influences their rates of MP removal. To probe this effect, the pseudo $2^{\text {nd }}$-order rate constant for BPA removal (BPA $k_{\text {obs }}$ ) was determined for all polymers under identical conditions (Fig. S5 $\dagger$ ). Among these non-porous samples, the BPA $k_{\mathrm{obs}}$ is correlated to phenolate concentration, even though BPA is a neutral molecule. We speculate that the phenolated polymers are more hydrophilic, which lead to faster diffusion of BPA-contaminated water into the polymer network. In addition, the differences in $S_{\mathrm{BET}}$ also affect BPA $k_{\text {obs }}$. Porous TFN-CDP-2 has a significantly higher surface area than non-porous TFN-CDP-3 through TFN-CDP-5 and has a BPA $k_{\text {obs }} 1-2$ orders of magnitude higher than the other polymers (1.61 and $0.02-0.23 \mathrm{~g} \mathrm{mg}^{-1} \mathrm{~min}^{-1}$, respectively). These experiments demonstrate that both phenolation and porosity affect the rate of BPA removal.

\section{Conclusions}

An improved understanding of the $S_{N} A r$ polycondensation of aliphatic alcohols and TFN was achieved using model etherification reactions, the first in depth such studies for TFN and aliphatic alcohols. These findings were adapted to synthesize TFN-CDPs with varying phenolate contents. The results show that the main factors in controlling the inclusion of phenolic functional groups are concentration of the reaction and rate of base addition. Polymers with higher concentrations of phenolic functionalities had higher affinity for 81 MPs, particularly those that are positively charged, as well as higher $\mathrm{Pb}^{2+}$ binding capacity. These results suggest that high phenolate content in TFN-CDP is key for $\mathrm{Pb}^{2+}$ ion capacity and MP affinity. Finally, this study demonstrates that the rational synthesis of TFN-CDPs can be achieved by controlling the rate of $\mathrm{K}_{2} \mathrm{CO}_{3}$ addition and the concentration of reactants. Future studies will focus on the incorporation of chelating groups to increase the capacity of CDPs for lead ion binding and expand the application of CDPs to the removal of other heavy metal ions.

\section{Conflicts of interest}

D. E. H. and W. R. D. serve on the scientific advisory board and own equity and/or stock options in CycloPure, Inc., which is commercializing related cyclodextrin polymers.

\section{Acknowledgements}

M. J. K., A. A., and W. R. D. were supported by the Center for Sustainable Polymers (CSP) at the University of Minnesota, a National Science Foundation (NSF) supported Center for Chemical Innovation (CHE-1413862). Y. L. and D. E. H. were supported by an NSF EAGER grant (grant number CHE-1541820) and by Cornell University's David R. Atkinson Center for a Sustainable Future (ACSF). This research made use of the Cornell Center for Materials Research User Facilities, which are supported through the NSF MRSEC program (DMR-1120296), the IMSERC at Northwestern University, which has received support from the NSF (CHE-1048773); Soft and Hybrid Nanotechnology Experimental (SHyNE) Resource (NSF ECCS-1542205); the State of Illinois and International Institute for Nanotechnology (IIN). Metal analysis was performed at the Northwestern University Quantitative Bio-element Imaging Center (QBIC).

\section{References}

1 C. M. G. Carpenter and D. E. Helbling, Environ. Sci. Technol., 2018, 52, 6187-6196.

2 S. D. Richardson and T. A. Ternes, Anal. Chem., 2018, 90, 398-428.

3 S. Masters, G. J. Welter and M. Edwards, Environ. Sci. Technol., 2016, 50, 5269-5277.

4 J. St Clair, C. Cartier, S. Triantafyllidou, B. Clark and M. Edwards, Environ. Eng. Sci., 2016, 33, 53-64.

5 T. Vorvolakos, S. Arseniou and M. Samakouri, Psychiatriki, 2016, 27, 204-214.

6 A. M. Vajda, L. B. Barber, J. L. Gray, E. M. Lopez, J. D. Woodling and D. O. Norris, Environ. Sci. Technol., 2008, 42, 3407-3414.

7 G. R. Tetreault, C. J. Bennett, K. Shires, B. Knight, M. R. Servos and M. E. McMaster, Aquat. Toxicol., 2011, 104, 278-290.

8 F. Gagne, B. Bouchard, C. Andre, E. Farcy and M. Fournier, Comp. Biochem. Physiol., Part C: Toxicol. Pharmacol., 2011, 153, 99-106.

9 E. Diamanti-Kandarakis, J. P. Bourguignon, L. C. Giudice, R. Hauser, G. S. Prins, A. M. Soto, R. T. Zoeller and A. C. Gore, Endocr. Rev., 2009, 30, 293-342.

10 S. G. Zimmermann, M. Wittenwiler, J. Hollender, M. Krauss, C. Ort, H. Siegrist and U. von Gunten, Water Res., 2011, 45, 605-617.

11 A. Joss, H. Siegrist and T. A. Ternes, Water Sci. Technol., 2008, 57, 251-255.

12 C. Prasse, M. Wagner, R. Schulz and T. A. Ternes, Environ. Sci. Technol., 2012, 46, 2169-2178.

13 J. Hollender, S. G. Zimmermann, S. Koepke, M. Krauss, C. S. McArdell, C. Ort, H. Singer, U. von Gunten and H. Siegrist, Environ. Sci. Technol., 2009, 43, 7862-7869.

14 J. Margot, C. Kienle, A. Magnet, M. Weil, L. Rossi, L. F. de Alencastro, C. Abegglen, D. Thonney, N. Chevre, M. Scharer and D. A. Barry, Sci. Total Environ., 2013, 461-462, 480-498.

15 P. A. Quinlivan, L. Li and D. R. Knappe, Water Res., 2005, 39, 1663-1673. 
16 G. Crini, Chem. Rev., 2014, 114, 10940-10975.

17 H.-J. Schneider, Angew. Chem., Int. Ed. Engl., 1991, 30, 14171436.

18 L. Liu and Q. X. Guo, J. Inclusion Phenom. Macrocyclic Chem., 2002, 42, 1-14.

19 C. Li, M. J. Klemes, W. R. Dichtel and D. E. Helbling, J. Chromatogr. A, 2018, 1541, 52-56.

20 Y. Ling, M. J. Klemes, L. Xiao, A. Alsbaiee, W. R. Dichtel and D. E. Helbling, Environ. Sci. Technol., 2017, 51, 7590-7598.

$21 \mathrm{H}$. Yamasaki, Y. Makihata and K. Fukunaga, J. Chem. Technol. Biotechnol., 2008, 83, 991-997.

22 J. Liu, Y. Yang, J. Bai, H. Wen, F. Chen and B. Wang, Anal. Chem., 2018, 90, 3621-3627.

23 Y. Yang, G. Hu, F. Chen, J. Liu, W. Liu, H. Zhang and B. Wang, Chem. Commun., 2015, 51, 14405-14408.

24 E. Yilmaz, S. Memon and M. Yilmaz, J. Hazard. Mater., 2010, 174, 592-597.

25 G. Crini, Dyes Pigm., 2008, 77, 415-426.

26 M. H. Mohamed, L. D. Wilson, J. V. Headley and K. M. Peru, Process Saf. Environ. Prot., 2008, 86, 237-243.

27 L. Xiao, Y. Ling, A. Alsbaiee, C. Li, D. E. Helbling and W. R. Dichtel, J. Am. Chem. Soc., 2017, 139, 7689-7692.

28 F. Zhao, E. Repo, D. Yin, L. Chen, S. Kalliola, J. Tang, E. Iakovleva, K. C. Tam and M. Sillanpaa, Sci. Rep., 2017, 7, 15811.
29 J. Hai, F. Chen, J. Su, F. Xu and B. Wang, Anal. Chem., 2018, 90, 4909-4915.

30 A. Alsbaiee, B. J. Smith, L. Xiao, Y. Ling, D. E. Helbling and W. R. Dichtel, Nature, 2016, 529, 190-194.

31 P. M. Budd, B. S. Ghanem, S. Makhseed, N. B. McKeown, K. J. Msayib and C. E. Tattershall, Chem. Commun., 2004, 230-231.

32 L. Wang, T. Chen, S. C. Chen, Q. Chen and M. Y. He, J. Heterocycl. Chem., 2014, 51, 1536-1540.

33 H. J. Mackintosh, P. M. Budd and N. B. McKeown, J. Mater. Chem., 2008, 18, 573-578.

34 N. B. McKeown and P. M. Budd, Macromolecules, 2010, 43, 5163-5176.

35 N. B. McKeown, P. M. Budd, K. J. Msayib, B. S. Ghanem, H. J. Kingston, C. E. Tattershall, S. Makhseed, K. J. Reynolds and D. Fritsch, Chem.-Eur. J., 2005, 11, 2610-2620.

36 I. Rose, C. G. Bezzu, M. Carta, B. Comesana-Gandara, E. Lasseuguette, M. C. Ferrari, P. Bernardo, G. Clarizia, A. Fuoco, J. C. Jansen, K. E. Hart, T. P. Liyana-Arachchi, C. M. Colina and N. B. McKeown, Nat. Mater., 2017, 16, 932-938.

37 J. He, Y. Li, C. Wang, K. Zhang, D. Lin, L. Kong and J. Liu, Appl. Surf. Sci., 2017, 426, 29-39. 